\title{
Association of genetic polymorphisms of GALNT3 and VDR with osteoporosis in postmenopausal women
}

\author{
GUORONG WANG, JUNHUA YANG, XUN ZHENG, JIAHUA ZHU, WANGQING SHI, \\ AIMIN CHEN, GUOXIAN CHEN and FANGYE ZHOU
}

Fujian Medical University Teaching Hospital, The First Hospital of Putian, Putian, Fujian 351100, P.R. China

Received May 6, 2016; Accepted August 23, 2016

DOI: $10.3892 /$ etm.2016.3665

\begin{abstract}
The correlation of genetic polymorphisms of GALNT3 and vitamin D receptor (VDR) with osteoporosis in postmenopausal women was investigated. A total of 1,212 cases of postmenopausal patients diagnosed with osteoporosis (observation group) and 404 cases of postmenopausal women without osteoporosis (control group) were selected. Dual-energy X-ray absorptiometry was used for measurement of bone mineral density (BMD) of lumbar vertebrae L2-4, proximal femoral neck and total hip, and classifications were made. TaqMan genotyping technology was employed to examine tag single-nucleotide polymorphism (tagSNP) of GALNT3 and VDR and the correlation of tagSNP with bone turnover markers (BTMs) and serum calcium and phosphorous levels was analyzed. The multiple logistic regression analysis was used to screen risk factors for osteoporosis. A comparison of age and menopause time of the two groups, yielded no statistical significance difference $(P>0.05)$. BMD and $\mathrm{T}$ values of the lumbar vertebrae, femoral neck and total hip in the observation group were significantly lower than those in the control group, and the differences were statistically significant $(\mathrm{P}<0.05)$. A comparison of the degree of osteoporosis, yielded statistically significant differences $(\mathrm{P}<0.05)$. The proportion of tagSNP of 5 loci in GALNT3 and 3 loci in VDR in the observation group was significantly higher than that in the control group, and the differences were of statistical significance $(\mathrm{P}<0.05)$. Levels of 25-OHD3, $\beta$-CTX, P1NP and serum calcium in the observation group were lower than those in the control group and the level of serum phosphorus in the observation group was higher
\end{abstract}

Correspondence to: Dr Fangye Zhou, Fujian Medical University Teaching Hospital, The First Hospital of Putian, 389 Longdejing Street, Putian, Fujian 351100, P.R. China

E-mail: zhoufangye2016@163.com

Key words: GALNT3, vitamin D receptor, genetic polymorphism, osteoporosis, correlation, TaqMan genotyping technology, multiple logistic regression analysis, bone turnover markers, serum calcium and phosphorus than that in the control group, and all of these results were statistically significant $(\mathrm{P}<0.05)$. The result of the correlation analysis revealed that rs1425000 and rs757343 were negatively correlated with BTM and serum calcium and phosphorus levels $(\mathrm{P}<0.05)$. The result of the regression analysis revealed that 8 tagSNPs were independent risk factors for osteoporosis. Genetic polymorphisms of GALNT3 and VDR were closely associated with osteoporosis in postmenopausal women.

\section{Introduction}

The incidence of osteoporosis in postmenopausal women is $30-55 \%$. Clinical manifestations include increased bone fragility, easy occurrence of bone fracture, and relatively high lethal and disability rates caused by hip and vertebral fractures, which results in heavy financial burden for the families of patients and society, and has become a serious public health concern (1). The pathogenesis of osteoporosis (OP) is associated with environment and genetics (2). OP is featured by decreased bone strength and bone quality. Bone mineral density (BMD), which can reflect $70 \%$ of bone strength, is the main predictor of osteoporotic fracture and the best quantitative index of diagnosing OP and predicting fracture risk (3). BMD has a strong genetic tendency; twin studies and pedigree research have confirmed that the heritability of BMD can reach 60-90\% (4). In addition, bone quality has a close relationship with such factors as microstructure and the mineralization degree of bone tissue and properties of bone matrix (5). Calcium and phosphorus are the essential elements in the process of bone mineralization, the abnormal content of which can influence the bone reconstruction process and is also the manifestation of bone diseases (6).

Fibroblast growth factor (FGF) 23 is universally accepted as phosphatonin, achieved together with molecular chaperone Klotho (7). UDP-N-acetyl- $\alpha$-D-galactosamine-polypeptide: polypeptide $\mathrm{N}$-acetylgal-actosami-nyltransferase-3 (ppGalNacT3) encoded by GALNT3 is involved in O-glycosylation of FGF-23 and prevents the hydrolysis of FGF-23 by protease and thus protects its functional integrity (8). Serum 25-OHD3 is the main way in which circulation of vitamin D occurs in human body, the main function of which is to regulate the metabolism of calcium and phosphorus (9). There are at least 30 types of candidate genes concerning OP, of which genetic 
Table I. TaqMan probe sequence design.

\begin{tabular}{lll}
\hline Locus & \multicolumn{1}{c}{ Forward } & \multicolumn{1}{c}{ Reverse } \\
\hline rs1863196 & CAAATTCCACTTTTCCCCATTTTAT & GCTACATAATTAACAGCTATTAATA \\
rs6710518 & ACTAGAGCCTTTGGACAGTATCTGC & CGAAGATTAGAAGCCGCTGTAGCTG \\
rs4667492 & GACAAAATTTTACACTTATGCATGA & AAAAACTCTCAAACTAGGAATAGAA \\
rs1425000 & TAGGATCTGCCAGGGAAGAATAATG & TGATAATGGTTGATAGAGAGGCATT \\
rs13429321 & CCCTAAGTGTACAAAACACACAAAC & TCACTTTACTTGGAAAATTATTTC \\
rs2228570 & CCTCATGTCTTCTGTTGGAG & TGCATCTGACCCTGGACTTC \\
rs757343 & ATAAGGAAATACCTACTTTGCTGGTTT & TAGGTGCTCAATAAAGTTGCTAAG \\
rs731236 & GTAGAATAGAAGGAGGGAAGC & AGCTTCATGCTGCACTCAGGCT \\
\hline
\end{tabular}

polymorphisms of GALNT3 and vitamin D receptor (VDR) have been most intensively and extensively studied $(10,11)$.

The present study was conducted by screening the correlation of tag single-nucleotide polymorphism (tagSNP) with OP and the severe degree of osteoporosis to provide some references for the early identification of the high-risk patients.

\section{Materials and methods}

Information of object. The observation group comprised 1,212 cases of patients admitted to The First Hospital of Putian (Fujian, China) from January, 2010 to January, 2016 that were diagnosed with postmenopausal osteoporosis. The control group comprised 404 cases of participants without postmenopausal osteoporosis. Patients receiving oophorectomy and hormone treatment and with secondary osteoporosis diseases (diabetes, Cushing's syndrome, thyroid, nutrition deficiency, myeloproliferative, bone tumors, connective tissue and congenital diseases), severe cardiovascular and cerebrovascular diseases, hepatic renal dysfunction, poor compliance, and incomplete clinical data were excluded.

The study was accepted by the Ethics Committee of The First Hospital of Putian. Informed consent was received from patients and their families.

Research methods. Dual-energy X-ray absorptiometry (DXA Lunar; Norland Medical Systems, Inc., Tustin, CA, USA) was used with the unit of $\mathrm{g} / \mathrm{cm}^{2}$ to examine BMD of poster anterior position of lumbar vertebrae L2-4, left proximal femoral neck and total hip, and classifications were made: $\mathrm{T} \leq-2.5$ indicated osteoporosis; $-2.5<\mathrm{T}<-1.0$ meant osteopenia; $\mathrm{T} \geq-1.0$ indicated normal bone mass; $\mathrm{T} \leq-2.5$ and one or more than one fragility fractures indicated severe osteoporosis. TaqMan genotyping technology was employed to measure tagSNP of GALNT3 and VDR and multiple logistic regression analysis was used to examine the correlation of genotype of each locus with osteoporosis and different degrees, as well as the correlation of bone turnover markers (BTMs) with serum calcium and phosphorus levels. BTM was measured with the aid of Roche Elecsys E170 and levels of 25-OHD3, cross linked C-terminal telopeptide of type 1 collagen $(\beta-\mathrm{CTX})$, and amino-terminal procollagen of type 1 collagen (P1NP) were measured using an electrochemiluminescence immunoassay (ECLIA).
For TaqMan genotyping technology a DNA extraction kit (Tiangen Biotech Co., Ltd., Beijing, China) was employed to extract DNA. A NanoDrop 2000 micro ultraviolet spectrophotometer (Thermo Fisher Scientific, Inc., Waltham, MA, USA) was used to measure DNA concentration and the value of OD260/OD280. The selection and measurement of SNP were based on the public gene database, Entrez Gene database (http://www.ncbi.nlm.nili.gov/gene/) and HapMap (http:/hapmap.ncbi.nlm.nih.gov/). The frequency of the rare allele was required to be $>10 \%$ loci, $\mathrm{r} 2>0.8$ in tagSNP, and the chosen ones had to cover upstream and downstream regulatory regions of GALNT3 and positive loci in GWAS. Five loci in GALNT3 were examined: rs1863196 (base was changed to $A>G)$, rs6710518 (C>T), rs4667492 (T>C), rs1425000 $(\mathrm{A}>\mathrm{T})$, and rs13429321 (A>T); and 3 loci in VDR: rs2228570 $(\mathrm{C}>\mathrm{T})$, rs757343 $(\mathrm{A}>\mathrm{G})$, and rs731236 $(\mathrm{C}>\mathrm{T})$. TaqMan probe sequence design and primer sequence were supported by TaqMan SNP Genotyping design (Applied Biosystems, Foster City, CA, USA) and Primer Express software provided by ABI company (Table I).

PCR reaction system. The Applied Biosystems 7900 quantitative PCR system was used for the PCR reaction, 10X amplification buffer solution $3 \mu 1+\mathrm{dNTP}$ mixture $(10 \mathrm{mM}) 1 \mu \mathrm{l}+$ forward and backward primer $(5 \mu \mathrm{M})$ $0.5 \mu 1+$ template DNA $1.5 \mu 1+$ Taq DNA polymerase $0.5 \mu \mathrm{l}+\mathrm{Mg} 2^{+}(25 \mathrm{mM}) 3 \mu \mathrm{l}$, was used, to which water at $30 \mu \mathrm{l}$. The reaction conditions were $95^{\circ} \mathrm{C}$ for $5 \mathrm{~min}, 94^{\circ} \mathrm{C}$ for $30 \mathrm{sec}, 65^{\circ} \mathrm{C}$ for $30 \mathrm{sec}$, and $72^{\circ} \mathrm{C}$ for $60 \mathrm{sec}, 35 \mathrm{cycles}$, and $72^{\circ} \mathrm{C}$ for $5 \mathrm{~min}$. Amplification products were examined by agarose gel electrophoresis and sent to Shanghai Sangon Biological Engineering Technology and Services Co., Ltd. (Shanghai, China) for sequence measurement using an ABI PRISM 310 DAN Sequencer.

Statistical analysis. SPSS 19.0 statistical software (Chicago, IL, USA) was used for data processing, and measurement data are expressed as the mean \pm standard deviation. Comparison between groups was carried out using t-test. Countable data were expressed as the number of cases or percentage (\%). A comparison between groups was carried out using the $\chi^{2}$ test and alleles in accordance with Hardy-Weinberg balance was tested by the $\chi^{2}$ test. Correlation analysis was performed by Spearman's rho and multiple regression analysis using the 
logistic model. $\mathrm{P}<0.05$ was considered to indicate a statistically significant difference.

\section{Results}

Comparison of BMD. Age and menopause time for the two groups were compared, and differences were of no statistical significance $(\mathrm{P}>0.05)$.The $\mathrm{BMD}$ and $\mathrm{T}$ values of lumbar vertebrae, femoral neck and total hip in the observation group were significantly lower than those in the control group, and the differences were statistically significant $(\mathrm{P}<0.05)$. In addition, comparing the degree of osteoporosis, the differences were statistically significant $(\mathrm{P}<0.05)$ (Table II).

Comparison of tagSNP. The proportion of tagSNP of 5 loci in GALNT3 and 3 loci in VDR in the observation group was significantly higher than that in the control group (Table III), and differences were of statistical significance $(\mathrm{P}<0.05)$.

Comparison of BTM and serum calcium and phosphorus levels. Levels of 25-OHD3, $\beta$-CTX, P1NP and serum calcium in the observation group were obviously lower than those in the control group and the serum phosphorus level in the observation group was higher than that in the control group (Table IV), All the differences were of statistical significance $(\mathrm{P}<0.05)$.

The correlation of tagSNP with BTM and serum calcium and phosphorus levels. The correlation analysis revealed that rs1425000 and rs757343 had a significant negative correlation with serum calcium and phosphorus levels. (rs1425000 and 25-OHD3: $r=0.523, \mathrm{P}=0.016 ; \beta$-CTX: $\mathrm{r}=0.508, \mathrm{P}=0.020$; P1NP: $r=0.632, P=0.010$; serum calcium: $r=0.548, P=0.012$; serum phosphorus: $\mathrm{r}=0.451, \mathrm{P}=0.019$; rs757343 and 25-OHD3: $\mathrm{r}=0.476, \mathrm{P}=0.023$; $\beta$-CTX: $\mathrm{r}=0.516, \mathrm{P}=0.017$; P1NP: $\mathrm{r}=0.553$, $\mathrm{P}=0.013$; serum calcium: $\mathrm{r}=0.594, \mathrm{P}=0.010$; serum phosphorus: $\mathrm{r}=0.521, \mathrm{P}=0.015$ ).

Multiple logistic regression analysis. Osteoporosis was the dependent variable, while age, menopause time, tagSNP, BTM and serum calcium and phosphorus levels were the independent variables. The result shown by the model was that 8 tagSNPs were independent risk factors for osteoporosis (Table V).

\section{Discussion}

The inactivating mutant of GALNT3 can induce a rare autosomal recessive genetic bone disease, hyperphosphatemic familial tumoral calcinosis with manifestations of a high serum phosphorus level and wide distribution of ectopic calcification (12). GWAS of Duncan et al (13) reported 6 genes may be associated with BMD and bone fracture of postmenopausal women, one of which is GALNT3. The gene knockout mouse model, confirmed that the inactivating mutant of GALNT3 can increase bone mass. At present, polymorphic loci in VDR of BMD association studies are mainly focused on BsmI, FokI, TaqI, ApaI, Cox2 and Tru9I (14). However, different sample sizes from different areas may cause different results (15). This may be related to the different locus genetic polymorphisms 
Table III. Comparison of tagSNP, case (\%).

\begin{tabular}{lccccccccc}
\hline Group & Case no. & rs1863196 & rs6710518 & rs4667492 & rs 1425000 & rs13429321 & rs2228570 & rs757343 & rs731236 \\
\hline Observation & 404 & $123(30.4)$ & $56(13.9)$ & $72(17.8)$ & $102(25.2)$ & $82(20.3)$ & $50(12.4)$ & $125(30.9)$ & $43(10.6)$ \\
Control & 1,212 & $600(49.5)$ & $476(39.3)$ & $306(25.2)$ & $630(52.0)$ & $523(43.2)$ & $445(36.7)$ & $680(56.1)$ & $332(27.4)$ \\
$\chi^{2}$ & & 44.520 & 88.610 & 9.324 & 87.387 & 67.573 & 84.480 & 76.754 & 47.699 \\
P-value & & $<0.001$ & $<0.001$ & 0.002 & $<0.001$ & $<0.001$ & $<0.001$ & $<0.001$ & $<0.001$ \\
\hline
\end{tabular}

tagSNP, tag single nucleotide polymorphism.

Table IV. Comparison of BTMs and serum calcium and phosphorus levels.

\begin{tabular}{lccccc}
\hline Group & $\begin{array}{c}25-\mathrm{OHD} 3 \\
(\mathrm{ng} / \mathrm{ml})\end{array}$ & $\begin{array}{c}\beta \text {-CTX } \\
(\mathrm{ng} / \mathrm{ml})\end{array}$ & $\begin{array}{c}\text { P1NP } \\
(\mathrm{ng} / \mathrm{ml})\end{array}$ & $\begin{array}{c}\text { Serum calcium } \\
(\mathrm{mmol} / \mathrm{l})\end{array}$ & $\begin{array}{c}\text { Serum phosphorus } \\
(\mathrm{mmol} / \mathrm{l})\end{array}$ \\
\hline Observation & $18.6 \pm 4.5$ & $1.0 \pm 0.3$ & $63.8 \pm 10.5$ & $2.45 \pm 0.06$ & $1.12 \pm 0.07$ \\
Control & $12.3 \pm 4.2$ & $0.6 \pm 0.2$ & $42.7 \pm 12.3$ & $2.13 \pm 0.05$ & $1.20 \pm 0.06$ \\
$\mathrm{~T}$ & 8.624 & 7.545 & 13.667 & 6.524 & 6.302 \\
P-value & $<0.001$ & $<0.001$ & $<0.001$ & 0.019 & 0.021 \\
\hline
\end{tabular}

BTMs, bone turnover markers.

Table V. Multiple logistic regression analysis.

\begin{tabular}{|c|c|c|c|c|c|}
\hline tagSNP & $\beta$ & Wald & P-value & OR & $95 \% \mathrm{CI}$ \\
\hline rs 1863196 & 0.102 & 4.627 & 0.041 & \multicolumn{2}{|c|}{$1.3020 .034-2.362$} \\
\hline rs6710518 & 0.134 & 5.320 & 0.036 & \multicolumn{2}{|c|}{$1.6240 .147-3.234$} \\
\hline rs4667492 & 0.250 & 5.217 & 0.037 & \multicolumn{2}{|c|}{$1.3450 .328-2.857$} \\
\hline rs 1425000 & 0.326 & 5.039 & 0.039 & \multicolumn{2}{|c|}{$1.9640 .627-3.527$} \\
\hline rs 13429321 & 0.157 & 4.957 & 0.040 & \multicolumn{2}{|c|}{$2.3211 .302-3.567$} \\
\hline rs2228570 & 0.524 & 5.634 & 0.032 & \multicolumn{2}{|c|}{$2.0341 .204-2.867$} \\
\hline rs757343 & 0.642 & 5.847 & 0.027 & \multicolumn{2}{|c|}{$2.6251 .635-4.203$} \\
\hline rs731236 & 0.394 & 5.535 & 0.033 & \multicolumn{2}{|c|}{$2.1571 .324-3.635$} \\
\hline
\end{tabular}

tagSNP, tag single nucleotide polymorphism.

of the total population, indicating that the same diseases can have different locus polymorphisms and that the same locus polymorphisms can have different clinical manifestations. The mechanism through which locus polymorphisms induce occurrence of diseases is an area of investigation, namely the process of gene transcription, translation and expression. Further research may show stronger evidence for the occurrence and development of diseases and provide accurate targets for treatment and prevention.

In the present study, a comparison of age and menopause time of the two groups showed that the differences had no statistical significance; BMD and $\mathrm{T}$ values of lumbar vertebrae, femoral neck and total hip in the observation group were all significantly lower than those in the control group, and the differences were of statistical significance. The proportion of tagSNP of 5 loci in GALNT3 and 3 loci in
VDR in the observation group was significantly higher than that in the control group, and differences were statistically significant. The levels of 25-OHD3, $\beta$-CTX, P1NP and serum calcium in the observation group were obviously lower than those in the control group and the serum phosphorus level in the observation group was higher than that in the control group, with the differences being statistically significant. Correlation analysis revelaed that rs1425000 and rs757343 had a significant negative correlation with serum calcium and phosphorus levels. The result of the regression analysis indicated that 8 tagSNPs were independent risk factors for osteoporosis. Thus, genetic polymorphisms of GALNT3 and VDR were tightly associated with osteoporosis in postmenopausal women.

Investigating whether osteoporosis occurred after menopause and comparing patients with different degrees of osteoporosis, the study analyzed tagSNP polymorphisms of 5 loci in GALNT3 and 3 loci in VDR and selected 8 tagSNPs (the studies about them are relatively mature), which greatly improved the pertinence of the study. Analysis and the correlation test for BTMs and serum calcium and phosphorus levels were performed and risk factors were screened using the multiple regression model. In fact, there are many factors inducing diseases and genetic polymorphisms are just one of those factors. Additionally, there are many types of disease-causing genes and the roles that different genes play in disease are not very clear. Therefore, the type of genes that play a key role in inducing osteoporosis has not been confirmed.

\section{Acknowledgements}

The present study was supported by the Fujian Provincial Department of Science and Technology (no. 2014J01391) and Putian City Medical Science and Technology [no. 2012S01(1)]. 


\section{References}

1. Pisani P, Renna MD, Conversano F, Casciaro E, Di Paola M, Quarta E, Muratore M and Casciaro S: Major osteoporotic fragility fractures: risk factor updates and societal impact. World J Orthop 7: 171-181, 2016.

2. Majchrzycki M, Bartkowiak-Wieczorek J, Wolski H, Drews K, Bogacz A, Czerny B, Zagrodnik-Ułan E and Seremak-Mrozikiewicz A: Polymorphisms of collagen 1A1 (COL1A1) gene and their relation to bone mineral density in postmenopausal women. Ginekol Pol 86: 907-914, 2015.

3. Jang EJ, Lee YK, Choi HJ, Ha YC, Jang S, Shin CS and Cho NH: Osteoporotic fracture risk assessment using bone mineral density in Korean: a community-based cohort study. J Bone Metab 23 : 34-39, 2016.

4. Bosnyák E, Trájer E, Protzner A, Komka Z, Györe I, Szmodis M and Tóth M: Osteocalcin gene polymorphism and bone density in Hungarian athletes. Anthropol Anz: Mar 21, 2016 (Epub ahead of print).

5. Mori S: Bone quality and strength relating with bone remodeling. Clin Calcium 26: 17-27, 2016 (In Japanese).

6. Redmond J, Jarjou LM, Zhou B, Prentice A and Schoenmakers I: Ethnic differences in calcium, phosphate and bone metabolism Proc Nutr Soc 73: 340-351, 2014.

7. Kawai M: The FGF23/Klotho axis in the regulation of mineral and metabolic homeostasis. Horm Mol Biol Clin Investig: Mar 4, 2016 (Epub ahead of print).

8. Esapa CT, Hannan FM, Babinsky VN, Potter P, Thomas GP. Croucher PI, Brown MA, Brown SD, Cox RD and Thakker RV: $\mathrm{N}$-ethyl-N-Nitrosourea (ENU) induced mutations within the klotho gene lead to ectopic calcification and reduced lifespan in mouse models. PLoS One 10: e0122650, 2015.
9. Carter GD, Jones JC, Shannon J, Williams EL, Jones G, Kaufmann $M$ and Sempos C: 25-Hydroxyvitamin D assays: potential interference from other circulating vitamin D metabolites. J Steroid Biochem Mol Biol: Dec 21, 2015 (Epub ahead of print).

10. Li N, Wang X, Jiang Y, Wang W, Huang W, Zheng X, Wang Q, Ning Z, Pei Y, Li C, et al: Association of GALNT3 gene polymorphisms with bone mineral density in Chinese postmenopausal women: The Peking Vertebral Fracture study. Menopause 21: 515-521, 2014.

11. Ling Y, Lin H, Aleteng Q, Ma H, Pan B, Gao J and Gao X: Cdx-2 polymorphism in Vitamin D Receptor gene was associated with serum 25-hydroxyvitamin D levels, bone mineral density and fracture in middle-aged and elderly Chinese women. Mol Cell Endocrinol 427: 155-161, 2016.

12. Topaz O, Shurman DL, Bergman R, Indelman M, Ratajczak P, Mizrachi M, Khamaysi Z, Behar D, Petronius D, Friedman V, et al: Mutations in GALNT3, encoding a protein involved in O-linked glycosylation, cause familial tumoral calcinosis. Nat Genet 36: 579-581, 2004.

13. Duncan EL, Danoy P, Kemp JP, Leo PJ, McCloskey E, Nicholson GC, Eastell R, Prince RL, Eisman JA, Jones G, et al: Genome-wide association study using extreme truncate selection identifies novel genes affecting bone mineral density and fracture risk. PLoS Genet 7: e1001372, 2011.

14. Ziablitsev DS and Larin OS: Influence of single nucleotide polymorphisms of vitamin D receptor-gene on the level of osteoassociated hormones linkage with postmenopausal osteoporosis. Fiziol Zh 61: 21-27, 2015.

15. Zhang H, Tao X and Wu J: Association of calcitonin receptor gene polymorphism with bone mineral density in postmenopausal Chinese women: a meta-analysis. Arch Gynecol Obstet 291: 165-172, 2015. 